\title{
Üniversite Takımlarında Mücadele Eden Sporcuların Spora Katılım Motivasyonlarına Etki Eden Faktörlerin Belirlenmesi (Eskişehir Osmangazi Üniversitesi Örneği)
}

\author{
Mehmet YILDIRIM*
}

\begin{abstract}
Üniversite Takımlarında Mücadele Eden Sporcuların Spora Katılım Motivasyonlarına Etki Eden Faktörlerin Belirlenmesi (Eskişehir Osmangazi Üniversitesi Örneği)
\end{abstract}

Özet

Bu araştırma; üniversitelerde spor yapan öğrencilerin spora katıIım motivasyonlarını belirlemek amacıyla yapılmışır. Araştırmanın evrenini 2014-2015 eğitim-öğretim ylında Eskişehir Osmangazi Üniversitesinde öğrenim gören sporcu öğrenciler oluşturmaktadır. Araştırmanın örneklemini ise okullarını müsabakalarda temsil eden 160 sporcu öğrenci oluşturmuştur. Araştırmada veri toplama aracı olarak, kişisel bilgi formu ve Spora Katılım Güdüsü Ölçeği kullanılmıştır. Verilerin analizinde frekans analizi, aritmetik ortalama, $\mathrm{t}$ testi ve ANOVA testi kullanıımıştır. Araştırma sonucunda spor yapan üniversite öğrencilerinin spora katılım motivasyonu en yüksek hareket/aktif olma olarak bulunmuştur. Cinsiyet değişkinine göre hareket/aktif olma alt boyutunda kadın sporcuların lehine bir fark olduğu tespit edilmiştir. Sporcu öğrencilerin spora branşına göre de yarışma alt boyutunda farklılaştığı tespit edilmiştir.

Anahtar Kelimeler: Motivasyon, Spor, Sporcu, Üniversite
Determination of Factors Affecting Sports Participation Motivation of Players Who Make Sports in University Teams (Sample of Eskişehir Osmangazi University)

\section{Abstract}

This study was carried on in order to determine this sports participation motivation of university students who make sports. The universe of the study was constituted athletes student in Eskişehir Osmangazi University at 2014-2015 educational years. The sample of study is 160 students who were the representatives of their schools in sports activities. The data collecting instruments was used personal information form and Participation Motivation Questionnaire (PMQ). In the analysis of data was used frequency analyze, mean, $t$ tests and ANOVA test.Sports participation motivation of student athletes was found the highest as movement/being active factor. There is a difference in favor of female athletes at movement/being active by gender. According to sports branch was determined diversity at competition size.

Key Words: Motivation, Sports, Sportsman, University

\section{Giriş}

Çocukların ve genç bireylerin spora olan ilgisinin artması ile birlikte, genç sporcuların kişilik özelliklerinin ve yarışma kaygılarının ortaya konulması, antrenörlerin tutum ve davranışlarının tespit edilmesi, spora ve fiziksel etkinliğe katılan gençlerin etkinliklere katılmaya yönlendiren nedenlerin tanımlanması ve bu nedenlerin sınıflandırıması amacı ile (Gill ve ark., 1983; Gould, Feltz ve Weiss, 1985; Klint ve Weiss, 1987) spor psikolojisi alanında birçok araştırma yapılmaya başlanmıştır. Spora katılım motivasyonu (sport participation motivation) ile ilgili bu ilk araştırmalar, beceri gelişimi ve

\footnotetext{
* Mehmet YILDIRIM, Yrd.Doç.Dr., Bozok Üniversitesi, Spor Yöneticiliği Bölümü, mehmet2682@hotmail.com
} 
Mehmet YILDIRIM

öğrenimi, eğlence, fiziksel zindelik, arkadaş edinme ve başarmanın, spora katılıma etki eden en önemli faktörler olduğunu ortaya koymuştur (Gill ve ark., 1983).

Motivasyon kelimesi latincede "movere", kelimesinden türetilmiş ve hareket etmek, harekete geçmek, özendirmek, teşvik etmek anlamlarını içeren bir kavramdır (Richard, 1975). Bireylere karşı nasıl davranıldığı ve bireylerin yapmış oldukları bir iş hakkında neler hissettikleriyle ilgili bir durumdur. Türkçede karşılı̆ıı "güdüleme, isteklendirme, harekete geçirici, teşvik edici" terimleri şeklinde kullanılmaktadır (Düren, 2000). Motivasyon kavramını "Kişilerin belirli bir amacı gerçekleştirmek üzere kendi arzu ve istekleri ile davranmaları" şeklinde de tanımlamak mümkündür (Koçel, 2003). Spor ortamlarındaki davranışların açıklanmasında önemli bir role sahip olan bu kavram (Hardy ve ark., 1997) hem sosyal ortamların gelişimsel sonucu hem de rekabet, öğrenme, performans, devamlıık, antrenör davranışları gibi davranışsal değişikler üzerindeki gelişimsel etkilerinden dolayı bir çok spor branşının en ilginç sorunlarının merkezinde yer almaktadır (Duda, 1989; Vallerand ve ark., 1987).

Sporcuların motivasyonlarını daha iyi anlayabilmek için birkaç kavramsal kuram ileri sürülmüştür (Roberts, 1972). Bu kuramlarda orta nokta içsel motivasyon, dışsal motivasyon ve motive olamama davranışları üzerinde durulması gerekliliğidir (Deci, 1975; Deci ve Ryan, 1985, 1991).

\section{1. İçe Yönelik Motivasyon}

Içce yönelik motivasyon, (IM) kişinin kendi kendini motive etmesi durumudur (Nicholas ve Robert, 1992). Yapılan bir aktivite esnasında elde edilen zevk ve tatmin için o aktivitenin yapılması anlamına gelir (Deci, 1975). İçsel olarak motive olan kişiler becerikli olmak için içsel açlığa sahiptirler. Başarıyı yakalayabilmek için kendilerini yönetebilme özelliğini taşımaktadırlar (Nicholas ve Robert, 1992). Bir kişinin içsel motivasyonu sağlandığında tüm dış engellemelere ve materyal eksikliğine rağmen göstermiş oldukları davranışı gönüllü olarak sergilemeye devam edecektir (Deci ve Ryan, 1985). Çünkü yapmış oldukları aktivite (spor) hakkında daha fazla şeyler öğrendikçe onu daha ilginç bularak tatmin olacaklardır. Böylelikle kendi kendilerine motive olmayı kabul ederek katılımlarını devam ettirebileceklerdir (Deci, 1975; White; 1959).

\subsection{Dışa Yönelik Motivasyon}

Dışa yönelik motivasyon diğer insanlar aracılığı ile gelen, olumlu ya da olumsuz etkilerde bulunabilen, davranışın tekrarlanma olasılığını arttırıp azaltabilen, maddi ve manevi değerler taşıyabilen güçlendirme ve pekiştirmelerdir (Iğdır PDR Kom., 2016; 1-8). Iç̧e yönelik motivasyonun aksine dışa yönelik motivasyon kendi iyiliği için değil bir amaç için sona ulaşmak adına göstermiş olduğu davranışların çeşitliliğini içermektedir. Kendi kendine olmayan ve sadece dış etkenler aracılıyla (ödül, alkış, takdir edilme, övülme vb) gerçekleşen davranışlardır (Ryan ve ark., 1990). 


\subsection{Motive Olamama}

Motivasyonun bu şekli öğrenilmiş çaresizlik kavramı ile benzerlik göstermektedir (Abramson Seligman, ve Teasdale, 1978). Yani motivasyonu sağlanamayan bireyler yapmış oldukları eylemler ve bu eylemlerin sonuçları arasında durumları algılayamazlar. Kendilerini beceriksiz olarak hissederler ve kontrol eksikliği yaşarlar. Ne içsel ne de dışsal olarak motive olamadıklarından böyle bir durumda aktiviteye devam etmeleri için bir neden açıklayamazlar ve sonunda yapmış oldukları spor aktivitesinde devam etmeme kararı alırlar (Deci ve Ryan, 1985).

Gould (1982); spora katılım motivasyonu ile yapılan araştırmaların, antrenörlere ve yöneticilere program hazırlamada yararlı olacağını, bu şekilde antrenörlerin aktivitelere katılan bireylerin ihtiyaçlarını daha kolay karşılayabileceğini, ihtiyaçları belirlenen ve bu doğrultuda aktiviteye yönlendirilen bireylerin psikolojik ve motorsal gelişimine olumlu etkide bulunacağını belirtmiş̧ir. Gill ve Williams' da (1996), spora katılım motivasyonu kavramının sadece genç sporcularla sınırlı kalmayarak yetişkinlerin fiziksel bir aktiviteye katılma nedenlerinin de belirlenmesinin önemi üzerinde durmuştur. Böylelikle yetişkinlerin spora katılma motivasyonları belirlenerek oluşturulacak spor programlarının isteklere ve ihtiyaçlara yanıt verecek şekilde daha verimli olmasına ve amaçlarına ulaşmasına katkıda bulunacağını ifade etmektedir.

Yapılan bu araştırmada üniversite spor takımlarındaki sporcu öğrencilerin yapmış oldukları spor branşına katılım nedenlerini belirlemek amaçlanmaktadır. Bu doğrultuda şu sorulara yanıt aranmıştır.

Üniversite takımlarında mücadele eden sporcuların;

- Spora katılım motivasyonu nedenlerinin önem derecesi nedir?

- Cinsiyet değişkenine göre spora katılım motivasyonu alt boyutları arasında istatistiksel olarak anlamlı bir fark mıdır? $(p<0.05)$.

- Spor branşı değişkenine göre spora katılım motivasyonu alt boyutları arasında istatistiksel olarak anlamlı bir fark mıdır? $(p<0.05)$.

\section{Yöntem}

Bu bölümde araştırma grubu, veri toplama araçları, verilerin analizinde kullanılan istatistik yöntem ve teknikler üzerinde durulmuştur.

\section{1. Çalışma Grubu}

Araştırmanın evrenini 2014-2015 eğitim-öğretim yılında Eskişehir Osmangazi Üniversitesinde öğrenim gören sporcu öğrenciler oluşturmaktadır. Araştırmanın örneklemini ise amaçlı örnekleme yöntemi kullanılarak belirlenen ve okullarını basketbol, futbol, hentbol ve voleybol branşlarında müsabakalarda temsil eden 160 sporcu öğrenci oluşturmuştur. 
Mehmet YILDIRIM

\subsection{Veri Toplama Araçları}

Ekonomik oluşu, uygulanabilirliği, dağınık ve büyük kitlelerden kısa zamanda bilgi alma imkânı sağlaması nedeniyle araştırmanın yürütülmesinde birincil kaynak araştırmaları arasında yer alan anket veri toplama aracı olarak tercih edilmiştir. Araştırmada verilerin toplanması amacıyla 2 adet veri toplama aracından yararlanılmıştır. Katılımcıların demografik bilgileriyle ilgili veriler " Kişisel Bilgi Formu" ile spora katılım motivasyonlarının belirlenmesine yönelik veriler ise Spora Katılım Güdüsü Ölçeği (Participation Motivation Questionnaire) ile elde edilmiştir.

\subsubsection{Spora Katılım Güdüsü Ölçeği}

Gill ve ark. (1983) tarafından geliştirilen spora katıım güdüsü ölçeği (PMQ), bireyin spora katılım nedenlerini içeren toplam 30 maddeden ve 8 alt boyuttan (başarı/statü, fiziksel uygunluk/enerji harcama, takım üyeliği/ruhu, arkadaş, eğlence, yarışma, beceri gelişimi, hareket/aktif olma) oluşmaktadır. Ölçek, "Çok Önemli (1)", "Az Önemli (2)", Hiç Önemli Değil (3)" şeklinde değerlendirildiği için elde edilen düşük değerler o maddenin daha önemli olduğunu göstermektedir. Çelebi (1993) tarafından ölçek Türkçeye çevrilmiş ve üniversite öğrencileri üzerinde güvenirliği analiz edilmiştir. Ölçekten elde edilen güvenirlik katsayısı 0.91 olarak bulunmuştur. Çelebi (1993) tarafından yapılan çalışmada spora katıım güdüsü ölçeğinin alt boyutlarına ilişkin güvenirlik katsayıları hesaplanmamıştır. Oyar ve arkadaşları (2001) tarafından ölçeğin alt boyutlarına ilişkin yapılan güvenirlik analizi sonucunda Cronbach Alpha iç tutarlılık katsayıları 0.61 (beceri gelişimi) ile 0.78 (başarı/statü) arasında bulunmuştur. Yapılan bu araştırmada ise Cronbach Alpha iç tutarlılık katsayıları 0.74 (başarı/statü) ile 0.77 (hareket /aktif olma) arasında değişmektedir. Ölçekten elde edilen toplam iç tutarlıık katsayısı ise 0.78 olarak tespit edilmiştir.

\subsection{Verilerin Analizi}

Araştırmada elde edilen veriler SPSS 18 istatistik paket programında analiz edilmiştir. Araştırma sonucundan elde edilen verilerin çözümlenmesinde katılımcıların demografik özelliklerini betimlemek amacıyla frekans analizinden, spora katıım güdüsü ölçeği maddeleri ve alt boyutlarının en önemlisinin belirlenmesi amacıyla ortalama ve standart sapma analizinden, cinsiyete göre spora katılım motivasyonları arasındaki farklılı̆ın belirlenmesi için t testinden ve spor branşına göre spora katılım motivasyonları arasındaki farklılığın tespit edilmesi amacıyla ise ANOVA testinden yararlanılmıştır. Karşılaştırmalarda 0.05 anlamlılık düzeyi esas alınmıştır.

\section{Bulgular}

Bu bölümde tanımlayıcı istatistiklere ilişkin bulgular ve farklılık testlerine ilişkin bulgulara yer verilmiştir. 
Tablo 1. Ölçek Formunu Yanıtlayan Sporcu Öğrencilere İlişkin Bulgular

\begin{tabular}{cccc}
\hline \hline & & $N$ & $\%$ \\
\hline \multirow{3}{*}{ Cinsiyet } & Erkek & 84 & 52.5 \\
& Kadın & 76 & 47.5 \\
& Basketbol & 36 & 22.5 \\
\multirow{3}{*}{ Spor Branşı } & Futbol & 47 & 29.4 \\
& Hentbol & 39 & 24.4 \\
& Voleybol & 38 & 23.8 \\
\hline
\end{tabular}

Araştırmaya toplam 160 spor yapan üniversite öğrencisi katılmıştır. Tablo 1'de görüldüğü gibi araştırmaya katılan sporcu öğrencilerin 84 (\%52.5)'inin erkek, 76 (\%47.5)'inin kadın olduğu belirlenmiştir. Sporcu öğrencilerin 36 (\%22.5)'i basketbol, 47 (\%29.4)'ü futbol, 39 (\%24.4) hentbol, 38 (\%23.8)'si voleybol branşı ile uğraşmaktadır.

Tablo 2. Spora Katılım Motivasyonu Nedenlerinin Önem Dereceleri

\begin{tabular}{lrrr}
\hline \hline Spora Katılım Motivasyonu Alt Boyutları & $N$ & $\bar{X}$ & $S s$ \\
\hline Başarı/Statü & & & \\
İyi olduğum bir konuda bir şeyler yapmak isterim. & 160 & 1.18 & 0.40 \\
Ödül kazanmayı seviyorum. & 160 & 1.41 & 0.61 \\
Önemli olduğumu hissetmek hoşuma gider. & 160 & 1.41 & 0.62 \\
Popüler olmak isterim. & 160 & 1.86 & 0.77 \\
Statü ve saygınlık kazanmak isterim. & 160 & 1.43 & 0.65 \\
Fiziksel Uygunluk/Enerji Harcama & & & \\
Enerjimi tüketmek istiyorum. & 160 & 1.56 & 0.65 \\
Formumu korumak istiyorum. & 160 & 1.25 & 0.54 \\
Stresimi atmak istiyorum. & 160 & 1.29 & 0.48 \\
Egzersiz yapmayı severim. & 160 & 1.31 & 0.50 \\
Fiziksel olarak sağlıklı olmak istiyorum. & 160 & 1.15 & 0.40 \\
Takım Üyeliği/Ruhu & & & \\
Takım çalışmasını severim. & 160 & 1.35 & 0.54 \\
Takım ruhunu severim. & 160 & 1.27 & 0.50 \\
Takımda olmayı severim. & 160 & 1.36 & 0.55 \\
Liderleri, antrenörleri ve eğiticileri severim. & 160 & 1.55 & 0.68 \\
Arkadaş & & & \\
Arkadaşlarımla olmak istiyorum. & 160 & 1.40 & 0.57 \\
Ailem ve yakın arkadaşlarım oynamamı istiyor. & 160 & 2.08 & 0.75 \\
Yeni arkadaşlarla tanışmak istiyorum. & 160 & 1.61 & 0.70 \\
Eğlence & & & \\
Seyahati severim. & 160 & 1.54 & 0.68 \\
Heyecanı severim. & 160 & 1.22 & 0.44 \\
Evden çımayı severim. & 160 & 1.56 & 0.66 \\
Eğlenceyi severim. & 160 & 1.20 & 0.43 \\
Yarışma & & & \\
\hline & & &
\end{tabular}


Mehmet YILDIRIM

\begin{tabular}{lrrr}
\hline Kazanmayı severim. & 160 & 1.20 & 0.44 \\
Rekabeti severim. & 160 & 1.36 & 0.55 \\
Meydan okumayı severim. & 160 & 1.57 & 0.68 \\
Beceri Gelişimi & & & \\
Becerilerimi geliştirmek istiyorum. & 160 & 1.13 & 0.36 \\
Yeni beceriler öğrenmek istiyorum. & 160 & 1.36 & 0.57 \\
Branşımda yükselmeyi isterim. & 160 & 1.26 & 0.51 \\
Malzeme ve tesislerden yararlanmak isterim. & 160 & 1.36 & 0.55 \\
Hareket/Aktif Olma & & & \\
Bir şeylerle uğraşmak hoşuma gider. & 160 & 1.28 & 0.51 \\
Hareketi severim. & 160 & 1.18 & 0.43 \\
\hline
\end{tabular}

Tablo 2'de sporcu öğrencilerin spora katılım nedenlerinin madde ortalamaları doğrultusunda önem dereceleri gösterilmiştir. Ölçekte yer alan maddeler 1 (Çok Önemli) ve 3 (Hiç Önemli Değil) arasında değerlendirildiğinden elde edilen düşük değerler o maddenin daha önemli olduğunu belirtmektedir. Sporcu öğrencilerin spora katılımlarını sağlayan en önemli nedenlerin "iyi olduğum konuda bir şeyler yapmak istiyorum $(\bar{x}=1.18)$ ", "fiziksel olarak sağlıklı olmak istiyorum ( $\overline{\mathrm{X}}=1.15)$ ", "takım ruhunu severim $(\overline{\mathrm{X}}=1.27)$ ", " arkadaşlarımla olmak istiyorum ( $\bar{X}=1.40)$ ", "eğlenceyi severim ( $\bar{X}=1.20)$ ", "kazanmayı severim $(\bar{X}=1.20)$ ", "becerilerimi geliştirmek istiyorum ( $\bar{x}=1.13)$ ", "hareketi severim $(\bar{x}=1.18)$ " olduğu tespit edilmiştir.

Tablo 3. Spora Katılım Motivasyonu Alt Boyutlarına i̇lişkin Bulgular

\begin{tabular}{lccc}
\hline \multicolumn{1}{c}{ Alt Boyutlar } & $N$ & $\bar{X}$ & Ss \\
\hline Başarı/Statü & 160 & 1.46 & .41 \\
Fiziksel Uygunluk/Enerji Harcama & 160 & 1.31 & .33 \\
Takım Üyeliği/Ruhu & 160 & 1.38 & .41 \\
Arkadaş & 160 & 1.70 & .49 \\
Eğlence & 160 & 1.38 & .39 \\
Yarışma & 160 & 1.38 & .42 \\
Beceri Gelişimi & 160 & 1.25 & .35 \\
Hareket/Aktif Olma & 160 & 1.23 & .40 \\
\hline
\end{tabular}

Tablo 3'de sporcu öğrencilerin spora katılım motivasyonları alt boyutları ile ilgili elde ettikleri puan ortalamaları gösterilmiştir. Sporcu öğrenciler Hareket/Aktif Olma ([?=1.23) boyutunu en önemli olarak görmektedir. En önemsiz gördükleri boyutun ise arkadaş boyutu (?]=1.70) olduğu belirlenmiştir. 
Tablo 4. Cinsiyet Değişkenine Göre Spora Katılım Motivasyonları Alt Boyutları Puan Ortalamaları t Test Bulguları

\begin{tabular}{lllllll}
\hline \hline \multicolumn{1}{c}{ Alt Boyutlar } & Cinsiyet & $N$ & $\bar{X}$ & Ss & $t$ & $p$ \\
\hline Başarı/Statü & Erkek & 84 & 1.47 & .43 & & \\
Fiziksel Uygunluk/ & Kadın & 76 & 1.44 & .39 & .401 & .689 \\
Enerji Harcama & Erkek & 84 & 1.35 & .35 & & \\
Takım Üyeliği/ & Kadın & 76 & 1.26 & .30 & 1.715 & .088 \\
Ruhu & Erkek & 84 & 1.39 & .44 & & \\
Arkadaş & Kadın & 76 & 1.37 & .38 & .220 & .826 \\
& Erkek & 84 & 1.68 & .49 & & \\
Eğlence & Kadın & 76 & 1.72 & .50 & -.519 & .604 \\
& Erkek & 84 & 1.37 & .36 & & \\
Yarışma & Kadın & 76 & 1.39 & .42 & -.314 & .754 \\
& Erkek & 84 & 1.32 & .39 & & \\
Beceri Gelişimi & Kadın & 76 & 1.43 & .45 & -1.622 & .107 \\
& Erkek & 84 & 1.26 & .38 & & \\
Hareket/ & Kadın & 76 & 1.25 & .32 & .132 & .895 \\
Aktif Olma & Erkek & 84 & 1.32 & .46 & & \\
\hline
\end{tabular}

Tablo 4'de sporcu öğrencilerin cinsiyetine göre spora katılım motivasyonları arasında hareket/aktif olma alt boyutunda kı öğrenciler lehine ([?=1.13) istatistiksel olarak anlamlı bir farklılık tespit edilmiştir ( $t=3.116 ; p<0.05)$.

Tablo 5: Spor Branşı Değişkenine Göre Spora Katılım Motivasyonları Alt Boyutları Puan Ortalamaları Anova Testi Bulguları

\begin{tabular}{llccccc}
\hline \hline \multicolumn{1}{c}{ Alt Boyutlar } & Spor Branşı & $N$ & $\bar{X}$ & Ss & $F$ & $p$ \\
\hline \multirow{3}{*}{ Başarı/Statü } & Basketbol(B) & 36 & 1.45 & .41 & & \\
& Futbol(F) & 47 & 1.42 & .44 & .191 & .902 \\
& Hentbol(H) & 39 & 1.49 & .44 & & \\
& Voleybol(V) & 38 & 1.47 & .36 & & \\
Fiziksel Uygunluk/ & Basketbol(B) & 36 & 1.26 & .34 & & \\
Enerji Harcama & Futbol(F) & 47 & 1.33 & .35 & .413 & .744 \\
& Hentbol(H) & 39 & 1.32 & .31 & & \\
Takım Üyeliği/Ruhu & Voleybol(V) & 38 & 1.33 & .33 & & \\
& Basketbol(B) & 36 & 1.36 & .37 & & \\
& Futbol(F) & 47 & 1.32 & .47 & .646 & .587 \\
& Hentbol(H) & 39 & 1.42 & .37 & & \\
& Voleybol(V) & 38 & 1.44 & .41 & & \\
\hline
\end{tabular}


Mehmet YILDIRIM

\begin{tabular}{lllllll}
\hline \multirow{3}{*}{ Arkadaş } & Basketbol(B) & 36 & 1.83 & .53 & & \\
& Futbol(F) & 47 & 1.58 & .47 & 1.732 & .163 \\
Hentbol(H) & 39 & 1.73 & .54 & & \\
Eğlence & Voleybol(V) & 38 & 1.68 & .42 & & \\
& Basketbol(B) & 36 & 1.31 & .33 & & \\
& Futbol(F) & 47 & 1.40 & .41 & .411 & .745 \\
Hentbol(H) & 39 & 1.40 & .41 & & \\
Yarışma & Voleybol(V) & 38 & 1.40 & .40 & & \\
& Basketbol(B) & 36 & 1.29 & .37 & & \\
& Futbol(F) & 47 & 1.26 & .32 & 3.354 & .021 \\
Beceri Gelişimi & Hentbol(H) & 39 & 1.50 & .48 & & \\
& Voleybol(V) & 38 & 1.47 & .48 & & \\
& Basketbol(B) & 36 & 1.21 & .36 & & \\
& Futbol(F) & 47 & 1.21 & .30 & 1.173 & .322 \\
Hentbol(H) & 39 & 1.34 & .39 & & \\
Aktif Olma & Voleybol(V) & 38 & 1.27 & .37 & & \\
& Basketbol(B) & 36 & 1.23 & .43 & & \\
& Futbol(F) & 47 & 1.22 & .40 & .090 & .966 \\
& Hentbol(H) & 39 & 1.25 & .39 & & \\
\hline
\end{tabular}

Tablo 5'de sporcu öğrencilerin spor branşına göre spora katıım motivasyonları arasında yarışma alt boyutunda istatistiksel olarak anlamlı bir farklılık tespit edilmiştir ( $F=3.354 ; p<0.05)$. Yarışma alt boyutunda spor branşı değişkenine göre gruplar arasındaki farklar az olduğundan çoklu karşılaştırma testi sonucunda istatistiksel olarak anlamlı bir farklılık bulunamamıştır.

\section{Tartışma ve Sonuç}

Bu araştırmada; üniversite spor takımlarında mücadele eden sporcu öğrencilerin spora katılım güdülerini belirlemek amaçlanmıştır. Araştırmaya, Eskişehir Osmangazi Üniversitesi spor takımlarında okullarını müsabakalarda temsil eden 160 kişi katılmıştır. Katılımcıların 84'ü (\%52.5) erkek, 76 'sı (\% 47.5) kadın sporcudur. Katılımcıların 36'sı (\% 22.5) basketbol, 47'si (\% 29.4) futbol, 39'u (\% 24.4) hentbol ve $38^{\prime} \mathrm{i}$ (\% 23.8) ise voleybol branşı ile uğraşmaktadır.

Sporcu öğrencilerin spora katılım güdülerinin belirlenmesi amacıyla gerçekleştirilen analizler sonucunda; uğraşmış oldukları spor branşına yönlenmelerindeki en önemli nedenlerin; "becerilerimi geliştirmek istiyorum (?=1.13)", "fiziksel olarak sağlıklı olmak istiyorum (?=1.15)", "iyi olduğum konuda bir şeyler yapmak istiyorum (??=1.18)", "hareketi severim (?]=1.18)" olduğu tespit edilmiştir. Hareket/aktif olma (?:=1.23) ve beceri gelişimi (?]=1.25) alt boyutlarının sporcu öğrenciler tarafından en önemli boyutlar oldukları belirlenmiştir. Gençlerin amaçlarına ulaşmaya yönelik en uygun aktivite içerisinde var olan yeteneklerini geliştirmeye çalıştıkları, yeni ilgi alanlarını keşfetmeye çaba gösterdikleri ve yapmış oldukları aktiveyle ilgili derinlemesine bilgiler kazanarak bu aktiviteye azimle devam 
etmeye çalıştıkları sonucuna varılabilir. Elde edilen bu sonuçlar, Stern ve ark. (1990), Gould ve ark. (1985), Brodkin ve Weis (1990), Klint ve Weis (1987), Ekmekçi ve ark. (2010), Aygün ve Yetim (2015) tarafından yapılan araştırma sonuçları ile benzerlik göstermektedir.

Araştırma bulgularında cinsiyet değişkenine göre spora katıım motivasyonları alt boyutları arasında hareket/aktif olma boyutunda istatistiksel olarak anlamlı bir farklılık olduğu bulunmuştur $(t=3.116 ; p<0.05)$. Kadın sporcuların erkek sporculara göre hareket/aktif olma boyutuna daha fazla önem verdikleri görülmüştür. Dengeli ve düzenli bir şekilde yapıldığında hareketli olmanın kas ve eklem yapısını geliştirdiğinin ve daha dirençli olunduğunun bilincinde oldukları bununla birlikte günlük yaşamın stresinden ve yoğunluğundan uzaklaşmak, yeni bir şeyler keşfetmek adına aktivitelere devam ettikleri sonucuna varılabilir. Araştırma sonuçları Gill ve ark.(1983), Gould ve ark. (1985) ve Oyar ve ark. (2001) tarafından yapılan araştırma sonuçları ile paralellik göstermektedir.

Araştırma bulgularına göre spor branşı değişkenine göre spora katılım motivasyonları alt boyutları arasında yarışma alt boyutunda istatistiksel olarak anlamlı bir farklılık tespit edilmiştir ( $F=3.354$; $\mathrm{p}<0.05)$. Yarışma alt boyutunda spor branşı değişkenine göre gruplar arasındaki farklar az olduğundan çoklu karşılaştırma testi sonucunda istatistiksel olarak anlamlı bir farklılık bulunamamıştır.

Araştırmada; gençlerin spora katııım güdülenmesinde dışsal güdülerden daha çok becerilerini geliştirmek, hareketi sevmek, sağlıklı olmak, kazanmayı sevmek, iyi oldukları konuda bir şeyler yapmak gibi içsel güdülerin daha etkili olduğu görülmüştür. Yapmış oldukları aktivitelerden elde etmiş oldukları haz ve tatmin o aktiviteye devam etmelerine sebep olmaktadır. Ryska (2003), Wang ve Biddle (2004)'de sporcularda centilmenlik ruhunun ortaya konulmasında ve motivasyonun daha yüksek düzeyde tutulmasında içsel güdülenmenin daha önemli olduğunu belirtmişlerdir.

Araştırmadan elde edilen sonuçların, çocuk ve gençlerin spora yönlenmelerini ve ilgi duydukları aktiviteler içerisinde keyif almalarını sağlamak adına yapılacaklar konusunda yol göstereceği düşünülmektedir. Yapılacak olan başka araştırmalarda aile, antrenör, öğretmen, arkadaş grubu, ekonomik, sosyal ve kültürel yapı gibi etmenlerinde değerlendirilerek gençlerin spora katıımlarını arttırmak hedeflenmelidir.

\section{Kaynaklar}

Abramson, L. Y., Seligman, M.E.P., Teasdale, J. D., (1978). Learned helplessness in humans: Critique and reformulation, Journal of Abnormal Psychology, 87, 49-74.

Aygün, M., Yetim, A. A., (2015). Ankara ilindeki 16-20 yaş arası buz hokeycilerin branşa katılım nedenleri, Journal of Research in Education and Society, 2 (1), 1-11.

Brodkin, P., Weis, M. R., (1990). Developmental diffrences in motivation for participating in competitive swimming, Journal of Sport and Exercise Psychology 12, 248-263.

Çelebi (Atalay), M., (1993). Orta Doğu Teknik Üniversitesi fiziksel aktivite kulüplerinde bulunan lider tipleri, Yayımlanmamış Yüksek Lisans Tezi, ODTÜ, Ankara.

Deci, E. L., (1975). Intrinsic motivation, Newyork, Plenum Press. 
Mehmet YILDIRIM

Deci, E. L., Ryan, R. M., (1985). Intrinsic motivation and self determination in human behavior, Newyork Plenum.

Deci, E. L., Ryan, R. M., (1991). A motivational approach to self: Integration in personal-ity. In R.Dientsbier (Ed.), Nebraska symposium on motivation, Vol:38. Perspectives on motivation 237-288, Lincoln: University of Nebraska Press.

Duda, J. L., (1989). Goal perspectives and behavior in sport and exercise settings. In C. Ames and M. Machr (Eds.), Advances in motivation and achievement, Vol:6, 81-115, Greenwich, CT.

Düren, A. Z., (2000). 2000'li yıllarda yönetim, Alfa Basım Yayım Dağıtım, İstanbul.

Ekmekçi, R., Arslan, Y., Ekmekçi, A., Ağbuğa, B., (2010). Üniversite öğrencilerinin spora bakış açılarının ve spora katılım güdülerinin belirlenmesi, New World Science Academy, 5, 104-114.

Gill, D. L., Gross, J. B., Huddleston, S., (1983). Participation motivation in youth sports, International Journal of Sport Psychology, 14, 1-14.

Gill, D., Williams, L., (1996). Competitive orientations and motives of adult sport and exercise participants, Journal of Sporth Behavior, 19(4), 307-319.

Gould, D., (1982). Sport psychology in the 1980s: Status, direction and challenge in youth sport research, Journal of Sport Psychology, 4, 203-215.

Gould, D., Feltz, D., Weiss, M., (1985). Motives for Participating in compettive youth swimming, International Journal of Sport Psychology, 4, 203-215.

Hardy, L., Jones, G., Gould, D., (1997). Understanding Psychological Preparation for Sport: Theory and Practice of Elite Performers. Chichester, West Sussex: John Wiley and Sons, 72-80.

Klint, A. K., Weiss, M. R., (1987). Perceived competence and motives for participating in youth sports: A test of Harter's competence motivation theory, Journal of Sport Psychology, 9, 55-65.

Koçel, T., (2003). İşletme Yöneticiliği, Beta Yayınları, İstanbul, 633-653.

Nicholas, J. G., Robert G. C., (1992). The general and the specific in the development and expression of achievement motivation, Motivation, Sport and Exercise, Human Kinetices Books, 65-69.

Oyar, B. Z., Aşçı, H. F., Çelebi, M., Mülazımoüğlu, M., (2001). "Spora Katılım Güdüsü Ölçeğinin Geçerlik ve Güvenirlik Çalışması", Hacettepe Spor Bilimleri Dergisi, 12 (2), 21-32.

Richard, M., (1975). Stres-Lyman W. Poter, (1975). Motivation and Work Behaviour, McGraw-Hill Series in Management.

Rsyka, T. A., (2003). Spormanship in young athletes: The role of competitiveness motivational orientation and perceived purposes of sport, The Journal of Psychology, 137(3), 273-292. 
Ryan, R. M., Connell, J. P., Grolnick, W. S., (1990). When achievement is not intrinsically motivated: A theory of self regulation in scholl. In A. K. Boggiano, Pittman, T. S., Achievement and motivation: A social-development perspective, New York Cambridge University Press.

Stern, H. P., Bradley, R. H., Prince, M. T., Stroh, S. E., (1990). Young children in recreation sports: Participation motivation, Clinical Pediatrics, 29, 89-94.

Vallerand , R. J., Deci, E. L., Ryan, R. M., (1987). Intrinsic motivation in sport, Exercise and Sport Sciences Review, 15, 389-425.

Wang, C. K. J., Biddle, S. J. H., (2004). Intrinsic motivation towards sports in Singaporean students: The role of sport ability beliefs, Journal of Health Psychology, 8, 515-523.

White, R. W., (1959). Motivation Reconsidered: The concept of competence, Psychological Review, 66, 297-333. 